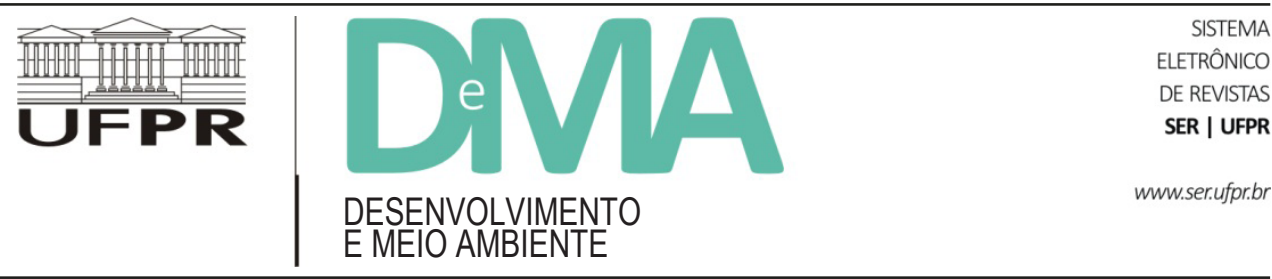

\title{
Sustentabilidade e educação ambiental na agricultura familiar: o caso de uma cooperativa no semiárido potiguar
}

\section{Sustainability and environmental education in family agriculture: the case of a cooperative in the Potiguar semi-arid}

\author{
Rosa Adeyse SILVA ${ }^{1 *}$, Maria Betânia Ribeiro TORRES ${ }^{2}$ \\ ${ }^{1}$ Faculdade do Complexo Educacional Santo André (FACESA), Assu, RN, Brasil. \\ ${ }^{2}$ Universidade do Estado do Rio Grande do Norte (UERN), Natal, RN, Brasil. \\ *E-mail de contato: rosaadeyse@gmail.com
}

Artigo recebido em 25 de abril de 2020, versão final aceita em 04 de setembro de 2020, publicado em 18 de dezembro de 2020.

RESUMO: O trabalho teve como objetivo identificar como a Cooperativa Potiguar de Apicultura e Desenvolvimento Rural Sustentável (COOPAPI) atua em processos formativos direcionados à educação ambiental e práticas sustentáveis junto aos agricultores cooperados. Para a obtenção dos dados da pesquisa, utilizou-se da entrevista semiestruturada, visando identificar de forma detalhada o sentido e o significado atribuídos pelos agricultores familiares à relação entre educação ambiental e sustentabilidade na agricultura familiar. $\mathrm{O}$ estudo revelou que a temática ambiental não é vivenciada por meio de formações que possam direcionar os agricultores a introduzirem a temática em sua ambiência de forma intencional; no entanto, os agricultores vivenciam a educação ambiental por meio de suas práticas diárias de cultivo. Ainda, os agricultores veem a cooperativa como facilitadora de práticas sustentáveis, visto que a cooperativa auxilia nas tarefas de orientar os agricultores no cultivo orgânico e fiscalização, mediante o mau uso de algum recurso.

Palavras-chave: práticas sustentáveis; agroecologia; COOPAPI; Apodi/RN.

ABSTRACT: The work aimed to identify how the Potiguar Cooperative of Apiculture and Sustainable Rural Development (COOPAPI) operates in training processes directed to environmental education and sustainable practices with cooperative farmers. To obtain the research data, a semi-structured interview was used, in order to identify in detail the sense and meaning attributed by family farmers as to the relationship between environmental education and sustainability in family farming. The study revealed that the environmental theme is not experienced through training that can direct farmers to introduce it in their ambience intentionally; however, farmers experience 
environmental education through their daily farming activities. Still, farmers see the cooperative as a facilitator of sustainable practices, since the cooperative assists in the tasks of guiding farmers in organic cultivation and inspects the misuse of resources.

Keywords: sustainable practices; agroecology; COOPAPI; Apodi/RN.

\section{Introdução}

As atividades agrícolas, como as demais atividades produtivas, são geradoras de impactos. Tornam-se, por vezes, irreversíveis os danos ambientais causados pela produção agrícola que maneja os recursos naturais de forma errônea. No entanto, acredita-se que com o acesso, pelo agricultor, a informações que possam auxiliar no manejo eficiente dos recursos naturais, esse cenário de degradação pode ser amenizado.

Barreto (2007) lembra que o manejo agrícola se caracteriza pela criação de agroecossistemas, o que consiste no sistema de cultivo com base no domínio dos sistemas naturais. Com isso, dada a "proximidade entre o agricultor e o meio natural, é importante conhecer a percepção que ele possui diante desse meio e de questões ambientais que se relacionam diretamente com sua atividade produtiva" (Barreto, 2007, p. 19).

Contudo, as discussões direcionadas à inclusão da Educação Ambiental (EA) no campo ainda são superficiais e incipientes. A aplicação do conceito de sustentabilidade na agricultura familiar implica se pensar na criação e no aperfeiçoamento de modelos de produção cada vez mais sustentáveis. Afinal, mesmo sendo a agricultura familiar detentora de práticas sustentáveis, como o reúso de água, as práticas da silagem e compostagem, entre outras, há a necessidade de introdução de pelo menos dois novos conceitos: a sustentabilidade estrutural, relacionada ao controle pelos agricultores ou agentes do trabalho agrícola sobre os recursos fundamentais a sua produção; e o conceito de sustentabilidade conjuntural, que diz respeito ao uso dos recursos existentes e a relação desses com os sistemas de produção e o ambiente, de um modo geral (Azevedo, 2002).

A carência de práticas ambientais sustentáveis no cenário agrícola familiar empobrece não só o simbolismo ambiental da ruralidade, mas também o crescimento social local, abrindo ainda mais espaços para as disparidades econômicas do setor, privando a agricultura familiar de promover o desenvolvimento sustentável. Como isso, este trabalho se propõe a identificar como a Cooperativa Potiguar de Apicultura e Desenvolvimento Rural Sustentável (COOPAPI) atua em processos formativos direcionados à educação ambiental e a práticas sustentáveis junto aos agricultores cooperados.

\section{Metodologia}

O método qualitativo foi o mais adequado para esta pesquisa, por se buscar informações de agricultores familiares, viabilizando identificar de forma detalhada o sentido e o significado atribuídos por eles à relação entre educação ambiental e sustentabilidade na agricultura familiar. A pesquisa de caráter descritivo foi desenvolvida no âmbito da COOPAPI, localizada no município de Apodi, Rio 
Grande do Norte, e delimitou-se, intencionalmente, a investigar somente a COOPAPI, referência na prática de agricultura familiar no RN.

A coleta de dados deu-se por meio de entrevistas semiestruturadas, realizadas com 15 agricultores cooperados, partindo de um universo de 206 agricultores cooperados, sem distinção de gênero, incluindo-se gestores da própria COOPAPI. Destaca-se que, dos 15 agricultores entrevistados, 14 residiam no Sítio Córrego e apenas um dos agricultores era do Assentamento Milagre. Contudo, essa não foi uma escolha preestabelecida pela pesquisa, pois a maioria das entrevistas se realizou no Sítio Córrego, sendo que o presidente da cooperativa foi entrevistado em Apodi. Para tanto, estabeleceu-se como critério de seleção dos sujeitos o fato de que fossem legalmente cooperados e desenvolvessem suas atividades agrícolas com o apoio da COOPAPI.

Utilizou-se como base um roteiro de entrevistas semiestruturado, contendo 10 questões, com a intenção de se fazer a caracterização dos agricultores cooperados, identificar seu perfil técnico e histórico e a descrição das práticas sustentáveis dos agricultores cooperados. Os dados coletados foram analisados com base na técnica de análise de conteúdo (Bardin, 1977; Bauer, 1989), classificando em categorias os significados similares. Assim, ao analisar de forma fragmentada todas as respostas dos agricultores, buscou-se identificar regularidades nos discursos.

Com isso, foram analisados quesitos e pontos subjetivos obtidos com as respostas das entrevistas semiestruturadas por meio da análise interpretativa, em que se observam as respostas interpretando-as por conceitos e palavras-chave adotados pela pesquisa, destacando-se pontos relevantes e transcrevendo-se algumas respostas, quando necessário, confrontando as afirmações dos entrevistados com os dados da pesquisa bibliográfica. Para auxiliar a operacionalização dessas análises qualitativas, utilizou-se o Software NVivo $\AA$, em que se codificaram as respostas dos 15 agricultores, tecendo o que o software denomina de "Nós", sendo estes os resultados ou palavras que geraram as "Nuvens de Palavras", apontando as mais frequentes dos nós.

\section{Construto da Educação Ambiental na agricultura familiar}

A Educação Ambiental inserida na agricultura familiar "direcionada ao desenvolvimento sustentável, é, incluir atores sociais presentes no campo em movimentos que promovam uma nova ressignificação dos homens do campo" (Dias \& Dias, 2017, p. 169). Finatto e Salamoni (2008) consideram que, ao se tratar da temática ambiental no meio rural, faz-se necessário destacar os processos de degradação que recebem um peso maior, tais como: a destruição de florestas nativas para o desenvolvimento de atividades agropecuárias; o desmatamento feito de forma indiscriminada e em grande escala; o uso abusivo e indiscriminado de agrotóxicos; e o perigoso aumento das concentrações de poluentes em águas de superfície e lençóis freáticos.

Não obstante, sabe-se que, na produção agrícola familiar, em sua maioria, os pequenos agricultores não se utilizam de grandes recursos, como maquinário ou contratação de mão de obra, já que a produção é, quase sempre, destinada ao consumo próprio. Ao retratarem a inserção da EA na agricultura familiar, Finatto e Salamoni (2008) afirmam que a convivência em cooperativas, grupos escolares, atividades de associação de moradores, 
entre outras organizações sociais, torna possível a criação de estratégias de cultivo e de ampliação da renda, partindo sempre da divulgação de informações para obtenção de um conceito ou elaboração de questões sobre EA.

A Educação Ambiental desenvolvida na agricultura familiar apresenta características e necessidades específicas diante do cenário rural. Na esfera formativa, por exemplo, os agricultores precisam "ser considerados como segmentos sociais que trazem consigo grande riqueza de conhecimento sobre os sistemas de produção de alimentos e de conservação do meio ambiente" (Bernal \& Martins, 2015 , p. 15). O conhecimento produzido no campo traz consigo técnicas, saberes e métodos que já se eternizaram e foram aperfeiçoados por gerações, destacando-se "as diversas tradições culturais e modos de produção e manejo ambiental praticados no Brasil" (Bernal \& Martins, 2015, p. 15).

No âmbito regional, Barbosa e Santos (2015) consideram a EA como um processo importante para a convivência dos agricultores no semiárido brasileiro, tendo em vista as particularidades geográficas e climáticas desse território, que acabam por exigir de seus nativos a descoberta de práticas que os auxiliem no manejo mais adequado dos recursos naturais. O semiárido brasileiro é composto por oito estados da região Nordeste (Alagoas, Bahia, Ceará, Paraíba, Pernambuco, Piauí, Rio Grande do Norte e Sergipe) e pelo Norte do Estado de Minas Gerais, sendo distribuído por 1.135 municípios, totalizando uma extensão territorial de 980.133,079 $\mathrm{km}^{2}$, correspondendo a $56,46 \%$ do território da região Nordeste e a $11,09 \%$ da região Sudeste (Medeiros et al., 2012).

Nos dias atuais, tem-se uma nova perspectiva para o desenvolvimento do semiárido do Nordeste, com uma concepção pautada no princípio de convivência com o ecossistema em que se está inserido. E essa concepção se orienta para o desenvolvimento sustentável, buscando uma maior compreensão sobre o clima e a vegetação, visando soluções que possam desenvolver novas tecnologias capazes de contribuir com as condições ambientais da região (Alves, 2013).

Para Baptista e Campos (2013), pensar sobre a Educação Ambiental no âmbito do semiárido é uma necessidade. Afinal, ela pode ser trabalhada na escola, utilizando-se da produção de conhecimentos que partem da realidade local, por meio dos processos de assistência técnica às comunidades, com o intuito de garantir maior qualidade de vida à população. Deste modo, poderá se priorizar uma boa relação entre os indivíduos e os recursos naturais, tanto no uso racional das águas, por exemplo, quanto na introdução dos princípios agroecológicos no manejo dos solos produtivos.

Silva, Rodriguez \& Meireles (2011) salientam que os principais problemas do semiárido vão além da seca, destacando a segurança alimentar, o colapso ambiental e o desprendimento da identidade local da região. Apontam, também, que os principais eixos de ações que solucionariam esses problemas consistem na diversidade, na necessidade de se conviver com a realidade do semiárido e com o vasto leque de atividades produtivas que a região oferece. Ressaltam, ainda, a necessidade de articulação para o desenvolvimento sustentável, o planejamento ambiental e territorial e a gestão de recursos hídricos e do solo, que também são desafios para as avaliações de caráter científico.

A cidade de Apodi, localizada na mesorregião do oeste potiguar, tem sua população estimada em 34.763 habitantes, sendo que 50\% destes são 
residentes da zona urbana e $50 \%$, da zona rural do município. Dessa porcentagem de $50 \%$ da zona rural, a maior parte é composta por agricultores familiares, homens e mulheres que se dedicam à produção de alimentos para o próprio consumo e para a comercialização (Lourenço et al., 2012).

Fernandes (2010) destaca que, em Apodi, o desenvolvimento local é baseado na agricultura familiar, que é intermediada pelas organizações sociais fundadas pelos agricultores familiares; com isso, além das associações comunitárias, o cooperativismo também é muito presente e forte na cidade. No campo da temática ambiental, as cooperativas e associações são as principais incentivadoras, atuando no desenvolvimento de "um trabalho consciente, em que a maioria dos cooperados busca a produção de forma orgânica, respeitando o meio ambiente". Deste modo, para que não haja o comprometimento da produção, "tendo em vista que o principal diferencial dos produtos é a sua organicidade", as cooperativas e associações comunitárias estão sempre engajadas em despertar, nos agricultores, a preocupação com a preservação ambiental e com a importância da agroecologia nos processos produtivos da agricultura familiar do município (Fernandes, 2010, p. 12).

Entretanto, compreender a agricultura requer também a compreensão de sua sustentabilidade. Para Cavalcanti (1998, p. 161), sustentabilidade diz respeito à "possibilidade de se obterem continuamente condições iguais ou superiores de vida para um grupo de pessoas e seus sucessores em dado ecossistema". O conceito de sustentabilidade começou a surgir na década de 1960, a partir das primeiras discussões mundiais sobre meio ambiente e com os questionamentos referentes aos modelos de desenvolvimento que se preocupavam somente com o crescimento econômico e com inovações para os sistemas de produção.

Chambers \& Conway (1992) dividem a sustentabilidade em dois grupos: ambiental e social. A sustentabilidade ambiental consiste na preservação ou no aprimoramento da base dos recursos produtivos, pensando nas gerações futuras; por sua vez, a social se refere à qualidade de vida do ser humano, sendo as duas indissociáveis, pois a sustentabilidade ambiental é um complemento para a sustentabilidade social.

$\mathrm{Na}$ conjuntura da agricultura, Costa (2010, p. 70) considera que "a agricultura sustentável tem provado ser um conceito, teoricamente, de uma extrema complexidade e ambiguidade, enquanto que na prática pode ser implementado apenas gradualmente e através de uma série de condições e compromissos". É impossível ter certeza se uma determinada prática, de fato, pode ser definida como sustentável, ou mesmo se um determinado conjunto de práticas pode ser constituído em sustentabilidade (Gliessman, 2000).

Cunha et al. (2012) salientam que há pelo menos duas linhas de pensamento quando se trata da aplicação da sustentabilidade na agricultura: a primeira delas objetiva o incentivo à adoção de práticas alternativas que sejam aplicadas ao cultivo e manejo agrícola; e a segunda vem elucidar a sustentabilidade como a capacidade para que as metas sejam alcançadas, orientando a agricultura a permanecer contínua diante das mudanças ambientais. Ehlers (1994), por seu turno, salienta que a agricultura sustentável é, na verdade, uma forma de pensar, podendo ser considerada uma filosofia. Com isso, o autor quis dizer que a agricultura sustentável não é uma metodologia ou prática agrícola que seja facilmente definida. 
Discussões sobre o papel da agricultura familiar vêm sendo cada vez mais exploradas por meio de debates que têm como foco o desenvolvimento sustentável, além da geração de emprego, de renda e da segurança alimentar. Ainda, faz-se necessário "resgatar a dívida social com a agricultora familiar em decorrência da agricultura moderna" (Gomes, 2004, p. 01).

A produção agroecológica que vem se desenvolvendo nas pequenas propriedades do território do semiárido nordestino, por exemplo, tem se destacado por ser uma atividade que motiva agricultores familiares a investirem mais em qualificação e na manutenção de práticas sustentáveis do que o manejo agroecológico oportuniza. Nessa perspectiva, a agricultura familiar praticada no sertão nordestino vem propiciando uma relação harmoniosa entre o homem e o meio natural. Com isso, a prática da agroecologia no semiárido é consolidada "na medida em que os agricultores familiares nutrem-se de uma visão mais aprofundada de sua relação com o meio", e assim, aliando os conceitos e métodos agroecológicos à sabedoria e experiência dos agricultores, as práticas sustentáveis vêm se estabelecendo nas atividades agrícolas familiares (Brasileiro, 2009, p. 09).

Em meio ao cenário nordestino, Dantas et al. (2007) apontam a zona rural do município de Apodi/RN, que se destaca pelo desenvolvimento de práticas sustentáveis em várias atividades da agricultura familiar. A apicultura, por exemplo, é uma atividade rentável para a região, cuja produção não se restringe somente ao mel de abelha, mas dá origem também a pólen, própolis, geleia, cera e veneno. Além do seu papel social em fomentar a renda para o homem no campo, a atividade apícola desenvolve no apicultor o cuidado ambiental, tra- duzido nas boas práticas de manejo das colmeias e das abelhas.

Nas comunidades rurais do município de Apodi/RN, as atividades de agricultores familiares promovem uma agricultura em que há respeito e cuidado do homem na relação com a natureza. A produção de forma diversificada vem garantindo a segurança alimentar e nutricional, fortalecendo a agroecologia na região, que é beneficiada com produtos livres de agrotóxicos (Dantas et al., 2007).

\section{Resultados e discussão}

No contexto da Educação Ambiental, a pesquisa revelou que o presidente e o tesoureiro da COOPAPI participaram de formações que traziam a EA como tema. O presidente afirmou, no entanto, que a cooperativa nunca promoveu nenhum curso diretamente voltado para a discussão da EA, muito embora já tenham discutido sobre as questões ambientais em reuniões e palestras. Questionados se sabiam o que significava EA, poucos agricultores afirmaram não saber do que se tratava, arriscando dizer que é: "ser educado com a natureza" (Agricultor Cooperado 01, 2018) e "respeitar a natureza" (Agricultor Cooperado 02, 2018). Nas palavras do tesoureiro: Educação ambiental é quando a gente preserva a
nossa mãe terra, não só onde você mora, mas preserva
onde estiver, você tem que preservar o meio ambiente.
Se você usar um copo descartável, é interessante que
você não jogue fora, é preservar onde você estiver.
Não queimar lixo, se você chegar lá fora em outro
município e a pessoa estiver queimando sem precisão,
é importante que você procure uma maneira que vocêe
diga: por que você está queimando? Qual o objetivo?
Ás vezes, a pessoa está queimando porque não tem 
conhecimento, quanto mais conhecimento melhor (Agricultor Cooperado 03, 2018).

Outros agricultores vincularam a EA à ação de não jogar lixo em qualquer espaço, mas procurar a destinação correta para cada resíduo e, principalmente, não fazer queimadas de lixo. Para um dos agricultores, EA “é cuidar bem do nosso meio, dos nossos recursos físicos, cuidar das nossas nascentes, é uma questão de se reeducar em pequenos gestos, papel, copos descartáveis que jogamos no meio da rua, acho que educação ambiental é melhorar mais isso" (Agricultor Cooperado 04, 2018).

Nesse mesmo contexto, uma agricultora afirmou que EA "é quando a gente trabalha respeitando nosso solo, nosso ar, trabalha de forma que esteja sempre preocupado com as questões ambientais, como as queimadas que geram fumaça, o lixo que vai prejudicar o solo" (Agricultora Cooperada 05, 2018). Finatto e Salamoni (2008) consideram que, ao se tratar da temática ambiental no meio rural, faz-se necessário destacar os processos de degradação que recebem um peso maior, tais como: a destruição de florestas nativas para desenvolvimento de atividades agropecuárias; o desmatamento feito de forma indiscriminada e em grande escala; o uso abusivo e indiscriminado de agrotóxicos; e o perigoso aumento das concentrações de poluentes em águas de superfície e lençóis freáticos.

Perguntados se praticavam EA em suas atividades agrícolas, alguns tiveram dúvidas em responder, mas outros entrevistados afirmaram que a praticavam. Aqueles que tiveram dúvidas em responder afirmaram que talvez praticassem por produzirem orgânicos e não utilizarem agrotóxicos. Já os que disseram praticar expuseram a economia de água e reaproveitamento de alimentos como práticas.
Outros agricultores responderam que praticam por meio dos quintais produtivos, por estarem inseridos na agricultura familiar e produzirem alimentos orgânicos, o que os deixam mais cientes dos cuidados que precisam ter com os recursos naturais.

Os agricultores foram também indagados se a COOPAPI havia promovido alguma formação/curso sobre EA e, de acordo com o próprio presidente, nenhum curso abordou diretamente essa temática. No projeto dos quintais produtivos, trabalhou-se muito a questão ambiental, pois, antes de os quintais serem introduzidos, os agricultores cooperados precisaram abrir mão de algumas práticas antigas: “[...] Então a gente buscou muito cuidar da questão orgânica, os cuidados com nosso lixo, resíduo orgânico e químico, considero que estamos sempre buscando melhorar esse caminho" (Agricultor Cooperado 06, 2018).

Um agricultor cooperado indicou ter participado de uma formação sobre EA em seu curso de graduação e complementou que o curso foi muito esclarecedor para as práticas de cuidado com o meio ambiente. Já outros agricultores afirmaram que as próprias reuniões da cooperativa reforçam muito a importância das práticas ambientais sustentáveis: "[...] O presidente está sempre reforçando que a nossa produção tem que ser 100\% orgânica" (Agricultor Cooperado 07, 2018).

Quando os agricultores cooperados foram perguntados se os conhecimentos adquiridos sobre práticas sustentáveis na COOPAPI influenciaram na mudança de comportamentos ou hábitos que eles consideravam errados, foram unânimes em afirmar que sim, pois se tratava de requisito para a inclusão em projetos da cooperativa. A mudança de hábito mais citada pelos agricultores foi a de não usarem mais agrotóxicos, bem como o orgulho em relação 
aos seus quintais produtivos, com culturas livres de qualquer veneno.

Para o presidente da COOPAPI, essa mudança foi um grande avanço, porque mudar a cultura das pessoas e fazer com que elas modifiquem o seu modo de produção não é uma tarefa fácil, pois: “[...]o principal desafio nosso, que eu entendo que vamos conseguir, é passar isso para os nossos filhos, para quando eles tiverem nossa idade, eles possam fazer melhor, pois nós não conseguimos fazer muito bem, não" (Agricultor Cooperado 06, 2018). O conhecimento produzido no campo traz consigo técnicas, saberes e métodos que já se eternizaram e foram aperfeiçoados por gerações, sendo destacadas "as diversas tradições culturais e modos de produção e manejo ambiental praticados no Brasil" (Bernal \& Martins, 2015, p. 15).

Por fim, aqueles que tiveram alguma formação em EA, quando indagados sobre os benefícios dos processos de EA para a produção agrícola, enfatizaram a respeito da melhoria da qualidade dos produtos. Segundo um agricultor: "Nessa parte de frutas, a gente vê que um tomate ou banana que é produzido com bastante agrotóxico, eles não têm a durabilidade que a orgânica tem" (Agricultor Cooperado 09, 2018).

Referente à nuvem de palavras gerada a respeito da participação dos agricultores cooperados em formação em EA, meio ambiente foi o termo mais falado pelos agricultores entrevistados (Figura 1).

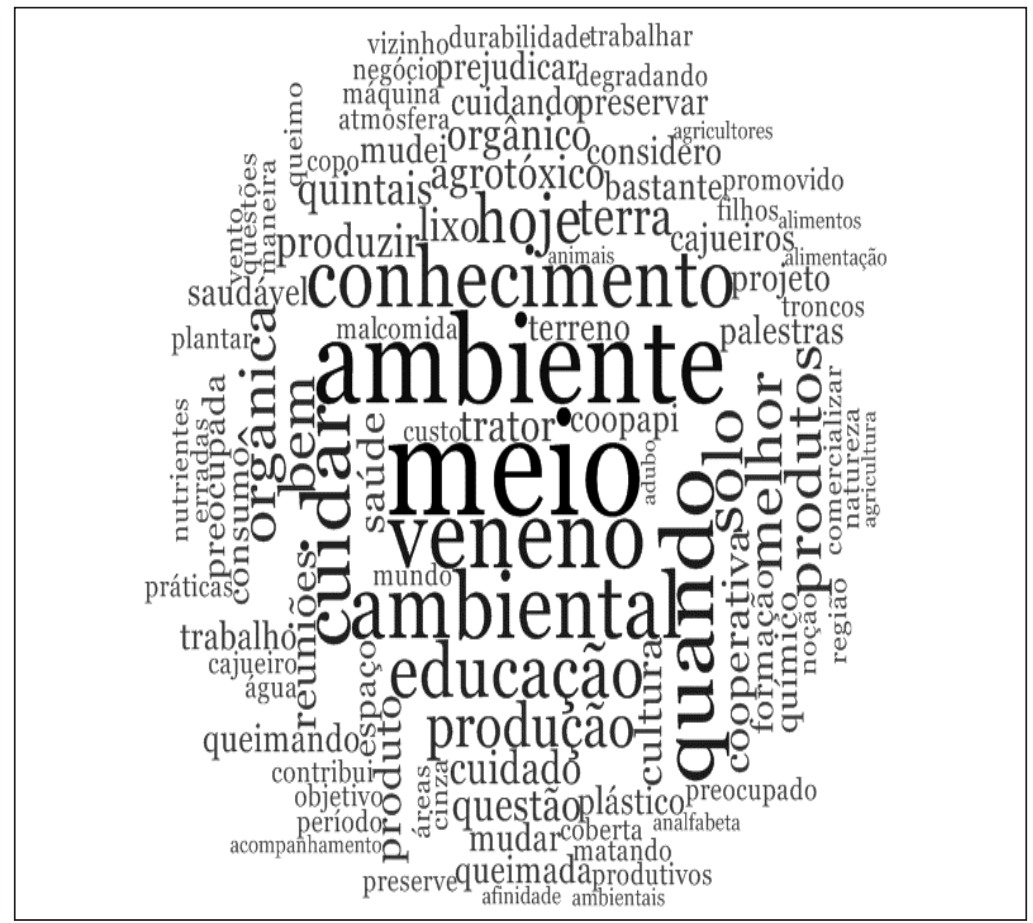

FIGURA 1 - Nuvem de Palavras da Participação dos Agricultores Cooperados em Formação sobre Educação Ambiental.

FONTE: Elaboração das autoras com base nas entrevistas e gerada pelo NVivo, 2019. 
Mais palavras, como conhecimento, orgânica, ambiental, educação, produção, solo, cuidar e melhor também receberam destaque. Bernal \& Martins (2015) explicam que a educação ambiental desenvolvida na agricultura familiar apresenta características e necessidades específicas, mediante o cenário rural. Nesse sentido, o conhecimento produzido no campo traz consigo técnicas, saberes e métodos que já se enraizaram na cultura dos agricultores. Assim, torna-se natural que a educação ambiental seja, quase sempre, associada ao meio ambiente, ou, no caso deste estudo, aos quintais produtivos, que se apresentam como o maior exemplo de EA para os agricultores cooperados, já que é por meio dos quintais que eles realizam práticas sustentáveis.

No aspecto das práticas ambientais sustentáveis, primeiramente buscou-se entender se os agricultores entrevistados utilizam ou se já chegaram a utilizar agrotóxicos na produção, e alguns deles responderam que já os usaram, mas reforçaram que não os utilizam mais. Um dos agricultores afirmou: "Já utilizei, sim. Quando eu não era da cooperativa, aí eu não sabia muito que prejudicava os alimentos" (Agricultor Cooperado 10, 2018). Outro disse: “Já usei, quando tinha praga no feijão" (Agricultor Cooperado 11, 2018):

Eu já usei, não posso mentir, já usei muito. Agora, a gente tem um inimigo hoje. Eu produzo, a minha banana é orgânica, meu tomate é orgânico, e se der só um tomate fico satisfeito, porque estou vendendo um produto de qualidade. Minha goiaba é orgânica, eu tenho uns dez pés de goiaba, até eu consegui aqui com o presidente da COOPAPI. Nada do meu quintal leva veneno, porque hoje eu tenho noção do mal que faz (Agricultor Cooperado 12, 2018).
Outros agricultores responderam nunca terem usado agrotóxicos. Nas palavras de um deles: " $A$ gente que produz orgânico não pode usar veneno" (Agricultor Cooperado 13, 2018). Brasileiro (2009) sustenta que a produção agroecológica que vem se desenvolvendo nas pequenas propriedades da região do semiárido nordestino, como é o caso do Sítio Córrego, tem se destacado por ser uma atividade que motiva agricultores familiares a investirem mais em qualificação e na manutenção das práticas sustentáveis que o manejo agroecológico oportuniza.

Questionados sobre o que fazem com o lixo, quando não têm uma lixeira por perto, os agricultores responderam que costumam guardar consigo até encontrarem uma lixeira. $\mathrm{O}$ fato que nos chama a atenção é a contradição existente nas falas, já que anteriormente o presidente da cooperativa afirmou que a cultura de manter os ambientes limpos não condiz muito com os agricultores cooperados. Mesmo assim, alguns insistiram em dizer que guardam o lixo em seus bolsos ou botas até que cheguem à casa e joguem no local certo. Então, foi lançada a pergunta: e qual seria o local correto? Nesse momento, não mais se falou em lixeiras, mas em buracos nos quintais e queimadas.

Os agricultores cooperados ainda foram questionados sobre as maneiras que procuravam para reduzir o consumo de recursos naturais disponíveis ou escassos, a exemplo da água. Nesse contexto, os agricultores relembraram os sistemas de irrigação utilizados nos quintais produtivos, bem como a reutilização da água que é consumida nas residências. Nas palavras de um agricultor:

A gente sempre procura reaproveitar tudo que dá p'ra reaproveitar, pois é a melhor forma possivel de dimi- 
nuir o consumo, procuro fazer muito isso, a água que usamos lá em casa, jogamos na grama, procuro botar nas plantas em volta da casa, na geladeira quando ficam mais garrafas boto nas plantas, faço de tudo para reaproveitar a água. Tenho uma criação de codorna, quando sobra água delas, misturo para botar nas plantas. Procuro reaproveitar tudo, nem sempre consigo, mas tento. E isso não é só com a água, tenho muito cuidado com a economia de energia também, porque às vezes a gente paga tão caro uma conta de energia, e não se dá conta que uma mudança de hábito, procurar manter acesas somente as luzes que são necessárias, podem diminuir os nossos gastos. [...] e na nossa produção, temos nosso sistema de irrigação, que nos permite consumir só o necessário, evitando o excesso e sempre buscando reaproveitar (Agricultor Cooperado 14, 2018).

No geral, os agricultores têm uma conduta de redução de consumo de água, tanto em suas residências quanto nas atividades da cooperativa, o que demonstra o uso inteligente desse recurso. Farias et al. (2012, p. 34) argumentam que a educação ambiental contextualizada no semiárido vem possibilitando a preservação dos recursos hídricos e divulgando para a população técnicas que orientam a preservação e a utilização racional da água, promovendo, ainda, discussões que evidenciam a importância das mudanças de hábitos para garantir a melhoria da qualidade de vida das gerações presentes e futuras. Nesse sentido, esses autores destacam, ainda, a necessidade de "[...] Oficinas, cursos, capacitação dos gestores, reuniões com a população, dentre outras, que além de divulgarem preceitos da sustentabilidade voltada para os recursos hídricos, forma[m] cidadãos mais ativos e críticos na sociedade, pois os permite interceder em questões que afetam diretamente o seu cotidiano".

Por fim, indagou-se sobre qual a razão ou o que lhes fizeram ter o cuidado e os comportamentos descritos. O presidente da COOPAPI acredita que os comportamentos foram se modificando a partir dos quintais produtivos, porque os agricultores teriam a chance de comercializar seus produtos que, por muitas vezes, eram desperdiçados por não ter mercado.

Já o tesoureiro da COOPAPI acredita que essas mudanças dependem de cada pessoa, sendo possível produzir orgânicos, vender orgânicos, mas ainda assim não compreende muito a importância disso, já que a comercialização é uma necessidade do agricultor. Nesse entendimento, os próprios agricultores concordaram que a maior parte dos hábitos foi modificada pelo engajamento na cooperativa:

Eu não acreditava antes nos orgânicos, a gente vinha e participava das reuniões, mas não colocava muita fé. Aí, na primeira vez que fui na feira orgânica, vi que ia ser muito melhor produzir só orgânicos (Agricultora Cooperada 15, 2018).

A agricultura orgânica tem se destacado como importante alternativa de fonte de renda para os pequenos agricultores familiares, justamente porque, mundialmente, os consumidores têm optado por alimentos mais saudáveis (Campanhola \& Valarini, 2001).

Quanto à nuvem de palavras gerada, na Figura 2, a palavra água foi o grande destaque nas práticas ambientais sustentáveis, seguida de palavras como casa, plantas, saúde, lixo, orgânico, mudar, veneno, cooperativa e produto.

Azevedo (2002) recorda que a agricultura familiar é detentora de práticas sustentáveis, como o reúso de água, as práticas da silagem e compostagem, entre outras, havendo a necessidade da introdução de, pelo menos, dois novos conceitos: a 


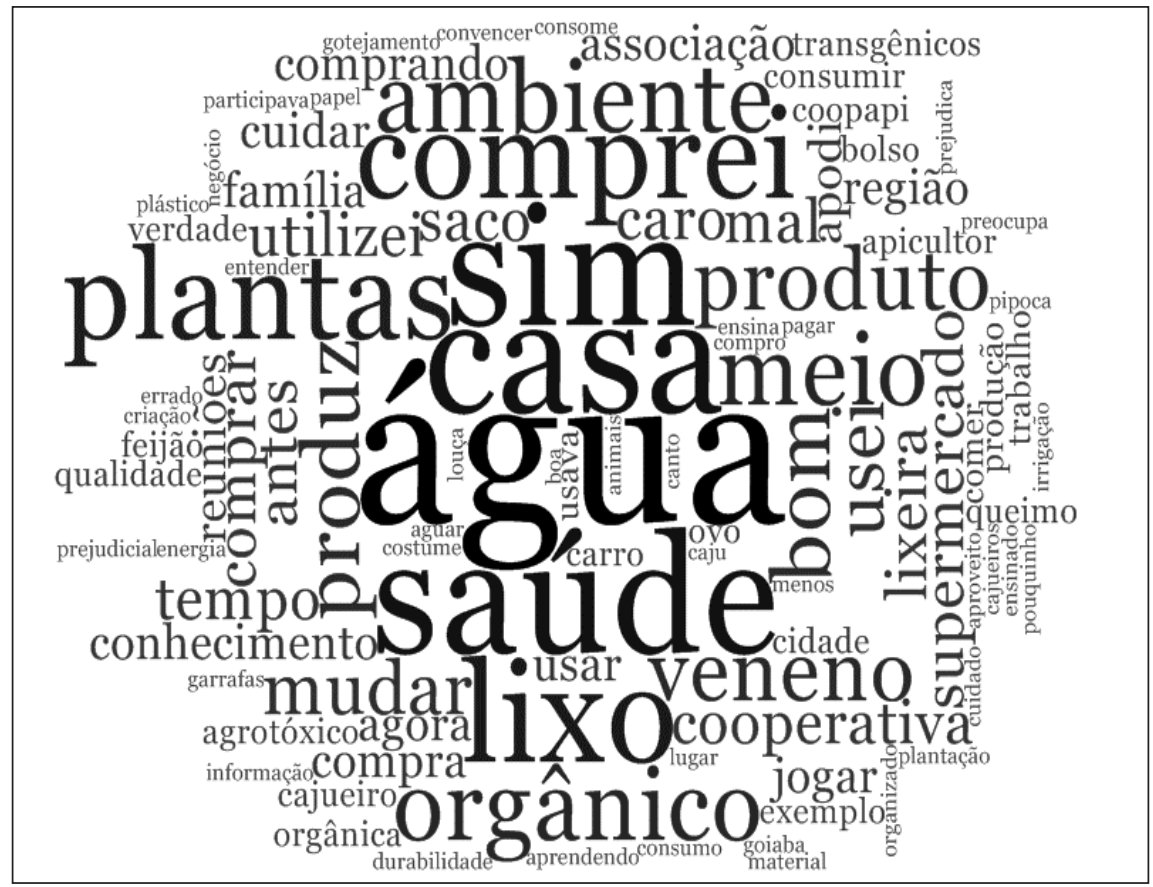

FIGURA 2 - Nuvem de Palavras das Práticas Ambientais Sustentáveis.

FONTE: Elaboração das autoras com base nas entrevistas e gerada pelo NVivo, 2019.

sustentabilidade estrutural, relacionada ao controle dos agricultores ou agentes do trabalho agrícola sobre os recursos fundamentais à sua produção; e o conceito de sustentabilidade conjuntural, que diz respeito ao uso dos recursos existentes e à relação destes com os sistemas de produção e o ambiente de um modo geral.

\section{Considerações finais}

A pesquisa realizada na cooperativa teve como objetivo geral identificar como a COOPAPI atua em processos formativos direcionados à educação ambiental e práticas sustentáveis junto aos agricultores cooperados. Dessa forma, o objetivo foi alcançado ao se observar que a temática ambiental não é vivenciada por meio de formações ou cursos que possam direcionar os agricultores a introduzirem a temática na sua ambiência de forma intencional, isto é, cientes de que praticam educação ambiental na agricultura familiar.

No entanto, os agricultores vivenciam a educação ambiental por meio de suas práticas diárias de cultivo. Assim, a temática ambiental é inserida nas atividades dos agricultores cooperados por meio do manejo agroecológico dos quintais produtivos, que lhes permitem entender que a água deve ser utilizada sem excessos, com inteligência, que a produção deve se desenvolver de forma natural, sem 
uso de agrotóxicos, e que o solo deve ser preservado, a fim de continuar produtivo. Outro aspecto revelado na pesquisa foi que a temática ambiental surge por meio de práticas como o uso consciente da água, por meio da implementação de sistemas de irrigação, como a microaspersão e o gotejamento, e, ainda, com o reúso da água oriunda de atividades domésticas, destinada à aguação das culturas dos quintais produtivos.

Os quintais produtivos, por sua vez, surgem como protagonistas das práticas ambientais sustentáveis, uma vez que se trata do ambiente e do motivo pelo qual os agricultores cooperados passaram a ampliar o seu conhecimento sobre a temática ambiental. Assim, os agricultores cooperados concordam que os quintais produtivos têm ensinado, na prática, alguns procedimentos característicos da produção agroecológica, a exemplo do entendimento de que as queimadas do solo, o uso de agrotóxicos e o desperdício de água não condizem com a prática agrícola familiar e com o que propõe a produção de orgânicos.

Ainda, os agricultores veem a cooperativa como grande facilitadora de práticas sustentáveis, visto que a cooperativa auxilia nas tarefas de orientar os agricultores no cultivo orgânico e na fiscalização, mediante o mau uso de algum recurso. Além disso, a cooperativa auxilia frente a outras práticas que não aprova, como o uso de agrotóxicos e as queimadas de lixo dentro dos quintais produtivos, o que acaba por tornar o solo improdutivo.

Entende-se, portanto, que a prática da Educação Ambiental direcionada à agricultura familiar deve se pautar em um constante diálogo, tendo como base o respeito a todas as formas de vida. $\mathrm{O}$ diálogo, deste modo, é necessário para a formação de cidadãos (agricultores e agricultoras) habilitados a construir um entendimento crítico sobre o mundo, por meio de suas ações, e buscando sempre tecer as mudanças que desejam. Talvez assim seja possível avistar para além das mudanças pontuais e individualizadas e enxergar na EA e nas práticas sustentáveis a concepção de uma luta coletiva que possa influenciar nas decisões de cunho governamental e na dinâmica da sociedade.

\section{Agradecimentos}

Ao CNPq/Universal Edital No 01/2016, processo No 426776/2016-0.

\section{Referências}

Alves, A. P. Convivência com o Semiárido. In: Conti, I. L.; Schroeder, E. O. (Orgs.). Estratégias de convivência com o Semiárido Brasileiro: textos e artigos de alunos(as) participantes. Brasília: IABS, 2013.

Azevedo, R. A. B. A Sustentabilidade da Agricultura e os Conceitos de Sustentabilidade Estrutural e Conjuntural. Rev. Agr. Trop., 6(1), 9-42, 2002. Disponível em: <http://www. ufmt.br/agtrop/Revista6/doc/01.htm>.
Baptista, N. Q.; Campos, C. H. Formação, organização e mobilização social no Semiárido Brasileiro. In: Conti, I. L.; Schroeder, E. O. (Org.). Convivência com o Semiárido Brasileiro: autonomia e protagonismo social. Fundação de Apoio da Universidade Federal do Rio Grande do Sul - FAURGS/REDEgenteSAN/Instituto Ambiental Brasil Sustentável - IABS/Agência Espanhola de Cooperação Internacional para o Desenvolvimento - AECID/Ministério 
do Desenvolvimento Social e Combate à Fome - MDS. Brasília-DF: IABS, 2013.

Barbosa, G. K.; Santos, E. M. Educação ambiental no semiárido: uma revisão sistemática das experiências e práticas. Revista de Educação Ambiental, 20(1), 2015. Disponível em: $<$ https://periodicos.furg.br/ambeduc/article/ view/5792/3715>.

Bardin, L. Análise de conteúdo. Lisboa: Edições 70, 1977.

Barreto, C. A. Agricultura e meio ambiente: percepções e práticas de sojicultores em Rio Verde-GO. 140 f. São Paulo-SP, Dissertação (Mestrado em Ciência Ambiental) Universidade de São Paulo - USP, 2007.

Bauer, M. W. Análise de conteúdo clássica: uma revisão. In: Bauer, M. W.; Corrêa, R. L. A rede urbana. São Paulo: Ática, 1989.

Bernal, A. B.; Martins, A. M. C. Programa de Educação Ambiental e Agricultura Familiar: Caderno conceitual do PEAAF. Brasília: MMA, 2015. Disponível em: <https:// www.mma.gov.br/publicacoes/educacao-ambiental/category/153-programa-de-educacao-ambiental-e-agricultura-familiar>.

Brasileiro, R. S. Alternativas de desenvolvimento sustentável no semiárido nordestino: da degradação à conservação. Scientia Plena, 5(5), 2009. Disponível em: <http:// observatorio.faculdadeguanambi.edu.br/wp-content/ uploads/2015/04/Brasileiro-2009.pdf $>$.

Campanhola, C.; Valarini, P. J. A agricultura orgânica e seu potencial para o pequeno agricultor. Cadernos de Ciência \& Tecnologia, 18(3), 69-101, set./dez. 2001.

Cavalcanti, C. Sustentabilidade da economia: paradigmas alternativos da realização econômica. In: Cavalcanti, C. (Org.). Desenvolvimento e natureza: estudo para uma sociedade sustentável. São Paulo: Cortez; Recife, PE: Fundação Joaquim Nabuco, 1998.

Chambers, R.; Conway, G. R. Sustainable Rural Livelihoods: practical concepts for the $21^{\text {st }}$ century. Institute of Development Studies: Discussion Paper no 296, 1992. Disponível em: <https://publications.iwmi.org/pdf/H_32821.pdf $>$.

Costa, A. A. V. M. R. Agricultura sustentável I: Conceitos. Rev. de Ciências Agrárias, 33(2), 61-74 dez. 2010.
Disponível em: <http://www.scielo.mec.pt/pdf/rca/v33n2/ v33n2a06.pdf $>$.

Cunha, G. R.; Dalmago, G. A.; Pires, J. L. F.; Pasinato, A.; Santi, A.; Gouvêa, J. A. Depois da Rio+20: Qual o futuro da "agricultura sustentável"? Revista Plantio Direto, 130, 10-17, jul./ago. 2012. Disponível em: $<$ https:// www.embrapa.br/documents/1355291/17775548/Gilberto+Cunha+et+al_RPD+v21\%2C+jul-ago+2012+-+Depois + da + Rio\%2B-E 20 .pdf/633bc342-a430-45bc-8588-0e$8 \mathrm{ff} 3 \mathrm{aa} 04 \mathrm{f} 2$ ? version $=1.0>$.

Dantas, B. L.; Liberalino Filho, J.; Lira, J. F. B.; Maracajá, P. B.; Diniz Filho, E. T. A agroecologia nos assentamentos de: Moaci Lucena, Sítio do Góis e Vila Nova em Apodi-RN. Informativo Técnico do Semiárido Grupo Verde de Agricultura Alternativa (GVAA), 1(1), 1-12, jan./mar. 2007. Disponível em: <https://www.gvaa.com.br/revista/index. php/INTESA/article/view/434>.

Dias, A. A. S.; Dias, M. A. O. Educação ambiental: a agricultura como modo de sustentabilidade para a pequena propriedade rural. Revista de Direitos Difusos, 68, jul.-dez. 2017. Disponível em: <http://ibap.emnuvens.com.br/rdd/ article/view/29>.

Ehlers, E. O que se entende por agricultura sustentável? 161 f. Dissertação (Mestrado em Ciência Ambiental) - Programa de Pós-Graduação em Ciência Ambiental, Universidade de São Paulo, São Paulo, 1994.

Farias, J. F.; Borges, F. R.; Silva, E. V. Educação ambiental contextualizada no semiárido cearense: subsídios à gestão $\mathrm{e}$ preservação dos recursos hídricos. Geosaberes, 3(5), 30-36, jan./jun. 2012. Disponível em: <http://www.geosaberes.ufc. $\mathrm{br} /$ geosaberes/article/view/145>.

Fernandes, F. A. O. A importância das cooperativas COOAFAP e COOPAPI na organização da agricultura familiar no município de Apodi/RN. 51 f. Monografia (Licenciatura em Geografia) - Universidade do Estado do Rio Grande do Norte - UERN, Caraúbas, RN, 2010.

Finatto, A. R.; Salamoni, G. Family agriculture and agroecology: profile of the agroecological production in the city of Pelotas/RS. Revista Sociedade \& Natureza, 20, 199-217, 2008. doi: 10.1590/S1982-45132008000200012 
Gliessman, S. R. Agroecologia: processos ecológicos em agricultura sustentável. Porto Alegre: Ed. FURGS, 2000.

Gomes, I. Sustentabilidade social e ambiental na agricultura familiar. Revista de Biologia e Ciências da Terra, 5(1), 2004. Disponível em: <https://www.redalyc.org/ pdf/500/50050107.pdf $>$.

Lourenço, N. P.; Luna, F. M.; Sousa, J. G. Cooperativismo, cooperação e território: um estudo de caso na Coopapi em Apodi-RN, Brasil. 2012. Disponível em: <http://observato-
riogeograficoamericalatina.org.mx/egal14/Geografiasocioeconomica/Geografiadelapoblacion/30.pdf $>$.

Medeiros, S. S. Cavalcante, A. M. B.; Perez. M. A. M.; Tinôco, L. B. M.; Hernan, S. I.; Pinto, T. F. (Org.). Sinopse do Censo Demográfico para o Semiárido Brasileiro. Campina Grande: Instituto Nacional do Semiárido - INSA, 2012.

Silva, E. V.; Rodriguez, J. M. M.; Meireles, A. J. A. (Orgs.). Planejamento ambiental e bacias hidrográficas (Tomo 1): Planejamento e gestão de bacias hidrográficas. Fortaleza: Edições UFC, 2011. 